\title{
ANALISA PENGARUH REDUKSI TERMAL TERHADAP KERUSAKAN STRUKTUR (STRUCTURAL-DISORDER) PADA LAPISAN TIPIS GRAPHENE OXIDE TEREDUKSI
}

\author{
Biaunik Niski Kumila ${ }^{1, a)}$, ChuanPu Liu ${ }^{2, b)}$ \\ ${ }^{1}$ Jurusan Fisika, Fakultas Sains dan Teknologi, Universitas Islam Negeri Walisongo, Jl. Walisongo No. 3-5, \\ Tambakaji, Ngaliyan, Semarang , 50185 \\ ${ }_{2}^{2}$ Jurisan Ilmu dan Teknik Material, Fakultas Teknik, National Cheng Kung University, No.1, Daxue Rd, Esat \\ District, Tainan City, Taiwan, 701
}

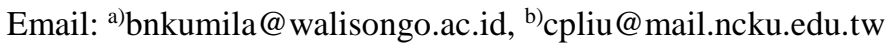

\begin{abstract}
Abstrak
Tujuan penelitian ini adalah menganalisa kerusakan struktur pada lapisan tipis graphene oxide setelah direduksi pada temperatur reduksi yang bervariasi. Lapisan tipis graphene oxide yang disintesis menggunakan metode Hummers direduksi secara termal pada variasi temperatur $350^{\circ} \mathrm{C}$ dan $850^{\circ} \mathrm{C}$ selama 2 jam dalam pemanas vakum $\left(\sim 10^{-3}\right.$ Torr $)$. Kuantitas defect sampel dikarakterisasi menggunakan Raman Spectroscopy sedangkan mikrostrukturnya dikarakterisasi menggunakan SEM (Scanning Electron Microscope). Persentase (kuantitas) defect pada graphene oxide dinyatakan dengan $\mathrm{I}_{\mathrm{D}} / \mathrm{I}_{\mathrm{G}}$. Nilai $\mathrm{I}_{\mathrm{D}} / \mathrm{I}_{\mathrm{G}}$ graphene oxide, graphene oxide tereduksi pada temperatur $350^{\circ} \mathrm{C}$ dan $850^{\circ} \mathrm{C}$ secara berurutan adalah $0.958,0.823$ dan 1.102 . Nilai $\mathrm{I}_{\mathrm{D}} / \mathrm{I}_{\mathrm{G}}$ tersebut menunjukkan bahwa kuantitas defect graphene oxide berkurang setelah direduksi pada suhu $350^{\circ} \mathrm{C}$ tetapi bertambah saat direduksi pada suhu $850^{\circ} \mathrm{C}$. Hasil gambar SEM menunjukkan bahwa lapisan tipis graphene oxide menkerut setalah direduksi pada temperatur $350^{\circ} \mathrm{C}$ dan berubah menjadi material seperti graphite berpori (porous stacked-layer graphite) setelah direduksi pada temperatur $850^{\circ} \mathrm{C}$.
\end{abstract}

Kata-kata kunci: graphene oxide tereduksi, reduksi termal, kerusakan struktur.

\begin{abstract}
The aim of this research is to analyse the structural-defect of graphene oxide reduced at various reduction temperatures. Graphene oxide thin film synthesized by Hummers method was thermally reduced at the temperature of $350^{\circ} \mathrm{C}$ and $850^{\circ} \mathrm{C}$ for 2 hours in vacuum condition $\left(\sim 10^{-3}\right.$ Torr). The presence of defects was characterized by Raman spectroscopy while the material's microstructure was characterized by SEM (Scanning Electron Microscope). A measure of defects existing on graphene oxide was represented by a ratio of $D$ peak intensity and $G$ peak intensity $\left(I_{D} / I_{G}\right)$. The $I_{D} / I_{G}$ value of raphene oxide and graphene oxide which is thermally reduced at $350^{\circ} \mathrm{C}$ and $850^{\circ} \mathrm{C}$ was $0.598,0.823$ and 1.102 , respectively. Those $\mathrm{I}_{\mathrm{D}} / \mathrm{I}_{\mathrm{G}}$ indicated that the quantity of defect was diminished after thermal reduction at $350^{\circ} \mathrm{C}$, yet it was increased after severe thermal reduction at $850^{\circ} \mathrm{C}$. SEM images of samples indicated the wrinkled graphene oxide thin film after thermal reduction at $350^{\circ} \mathrm{C}$ and it formed a porous stacked-graphite like material after severe thermal reduction at $850^{\circ} \mathrm{C}$
\end{abstract}

Keywords: reduced graphene oxide, thermal reduction, structural disorder . 


\section{PENDAHULUAN}

Sebagai material baru, aplikasi graphene sangat beragam mengingat graphene memiliki sifat kelistrikan, kimia, mekanik dan fisik yang sangat menakjubkan. Graphene memiliki Modulus Young dan Strength $\sim 130 \mathrm{GPa}(1)$, memiliki mobilitas elektron pada temperatur ruangan $\sim 2.5 \times 105 \mathrm{~cm} 2 \mathrm{~V}$ $1 \mathrm{~s}^{-1}(2)$ dan luas permukaan jenis yang besar (secara teoritik $2630 \mathrm{~m}^{2} / \mathrm{g}$ untuk single-layer graphene)(3) yang sangat cocok diaplikasikan sebagai sensor. Proses produksi graphene yang terkenal dan banyak digunakan adalah CVD (Chemical Vapor Deposition)-based graphene. Proses ini membutuhkan temperatur proses yang sangat tinggi (diatas $1000^{\circ} \mathrm{C}$ ) dan membutuhkan instrumen berteknologi tinggi (high-cost process). Berdasar pada permasalahan tersebut, para peneliti berlombalomba untuk mencari solusi sintesis graphene yang low-cost dan bisa diproduksi dalam jumlah banyak (mass-production).

Graphene oxide merupakan material alternatif pengganti graphene yang low-cost dan mudah disintesis. Selain itu, Graphene oxide merupakan jenis graphene yang hydrophilic karena memiliki oxygen functional group. Selain fraksi $\mathrm{sp}^{2}$, oksigen functional-group seperti hydroxyl, carboxyl, carbonyl dan epoxy inilah yang diasumsikan sebagai situs aktif yang sensitif sebagai sensor terhadap molekul-molekul adsorbates. Dalam aplikasinya sebagai sensor gas, oxygen functional group dan porus pada graphene oxide merupakan active-site yang sangat sensitif terhadap gas. Pengoptimalan jumlah active-site pada graphene oxide dapat dilakukan dengan memvariasi temperatur reduksinya. Pada penelitian ini, penulis akan menganalisa kerusakan struktur pada lapisan tipis graphene oxide yang direduksi pada temperatur yang bervariasi.

Graphene merupakan rising-star material yang sedang hangat diteliti oleh para peniliti, khususnya bidang Ilmu dan Teknik Material. Graphene kembali menjadi hot-topic pada tahun 2004 dan ditemukan bahwa graphene merupakan zero-gap material(4) Graphene memiliki struktur berupa $\mathrm{sp}^{2}$ karbon membentuk kisi segi enam dua dimensi (two-domensional $s p^{2}$-honeycomb lattice). Lapisan graphene dapat digulung membentuk 0 dimensi material yang disebut fullerene. Lapisan graphene juga dapat digulung membentuk 1 dimensi material berbentuk corong yang disebut nanotube. Sedangkan graphite merupakan kumpulan ratusan bahkan ribuan lapisan graphene (Gambar 1) (5).

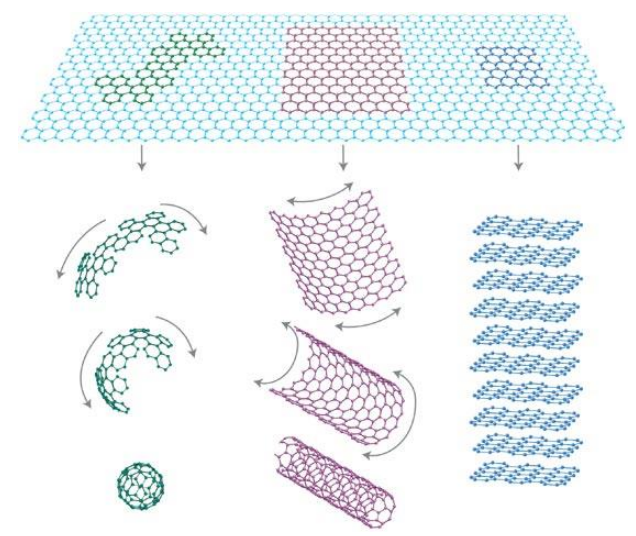

Gambar 1. Material Grafitik dalam berbagai bentuk. 2 dimensi Graphene (atas), 0 dimensi buckyballs (kiri bawah), 1 dimensi nanotube (tengah bawah), 3 dimensi graphit (kanan bawah)

Graphene oxide merupakan solution-based graphene yang disintesis dengan metode Hummers sebagai solusi dari permasalahan di atas (6). Proses sintesis graphene oxide lebih murah dan mudah dibandingkan CVD-based graphene. Akan tetapi, graphene oxide adalah resistive-material karena mengandung banyak oxyegen functional-group (7). Oxigen yang terkandung dalam graphene oxide kemudian direduksi dengan berbagai cara, seperti : reduksi termal dan redukci kimia menggunakan hydrazine, yang kemudian disebut graphene oxide tereduks (reduced graphene oxide). Hydrazine merupakan senyawa tak berwarna dan sedikit berbahaya yang biasa digunakan untuk mereduksi graphene oxide. (8). Selain proses reduksi menggunakan hydrazine (reduksi kimia), reduksi termal merupakan salah satu cara yang paling mudah dan non-toxic sebagai alternatif proses sintesis reduced graphene oxide. Proses sintesis reduced graphene oxide ditunjukkan oleh Gambar 2. 
Gambar 2 mununjukan skema umum proses oksidasi graphite menjadi graphene oxide dan proses reduksi graphene oxide menjadi reduced graphene oxide. Graphite sebagai raw material dioksidasi dengan menambah agen oksidasi (oxidation agent) seperti Potassium Permanganate yang menjadikannya lebih hydrophilic (mudah bereaksi dengan air dan pelarut lain) (9). Oksigen yang terkandung dalam graphene oxide kemudian dikurangi dengan reduksi termal atau reduksi kimia untuk mengembalikan sifat kelistrikannya.

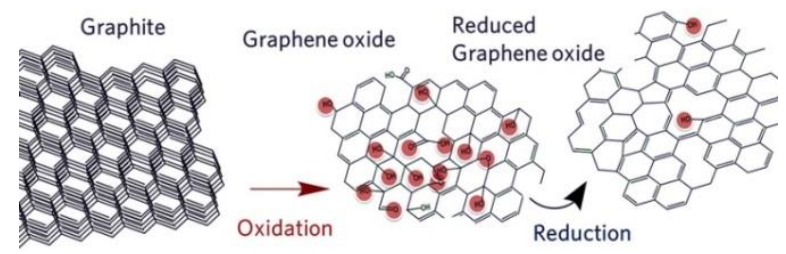

Gambar 2. Skema umum proses oksidasi graphite menjadi graphene oxide dan reduksi graphene oxide menjadi reduced graphene oxide.

\section{METODE PENELITIAN}

\section{Preparasi Lapisan Tipis Graphene Oxide}

Graphene oxide disintesis menggunakan metode Hummers dengan graphite sebagai material dasarnya. Serbuk graphite dilarutkan dalam Sulfuric acid $\left(\mathrm{H}_{2} \mathrm{SO}_{4}\right)$ dan ditambahkan serbuk Pottasium permanganate $\left(\mathrm{KMnO}_{4}\right)$ untuk membentuk oxygen-functional group yang kemudian kita sebut graphite oxide. Penambahan dilstilled water (aquades) disertai dengan sonication dipercaya mampu memisahkan lapisan-lapisan graphene oxide menjadi lapisan graphene oxide yang berdiri sendiri (free-standing graphene oxide layer). Prekursor graphene oxide pada penelitian ini disediakan oleh group research yang dipimpin oleh Professor Ruey-Chi Wang dari Jurusan Ilmu dan Teknik Material, National University of Kaohsiung, Kaohsiung, Taiwan.

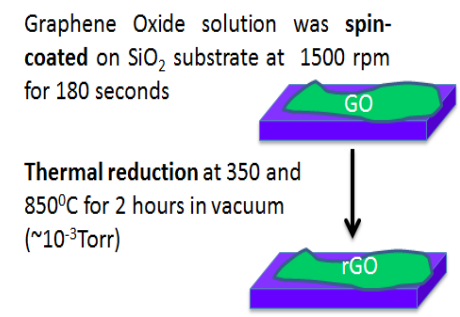

Gambar 3. Skema preparasi lapisan tipis graphene oxide

Preparasi lapisan tipis graphene oxide dibuat dengan meneteskan $10 \mu \mathrm{L}$ larutan graphene oxide pada substrat silikon dioksida $\left(\mathrm{SiO}_{2}\right)$ selebar $1 \mathrm{~cm}^{2}$. Pembuatan lapisan tipis pada substrate menggunakan metode spin-coating dengan spin-rate $1500 \mathrm{rpm}$ selama 180 detik. Pelapisan dilakukan sebanyak 2 kali. Lapisan tipis graphene oxide kemudian direduksi secara termal pada temperatur $350^{\circ} \mathrm{C}$ dan $850^{\circ} \mathrm{C}$ selama 2 jam dalam vacuum furnace $\left(\sim 10^{-3}\right.$ Torr) (Gambar 3 dan 4$)$. 


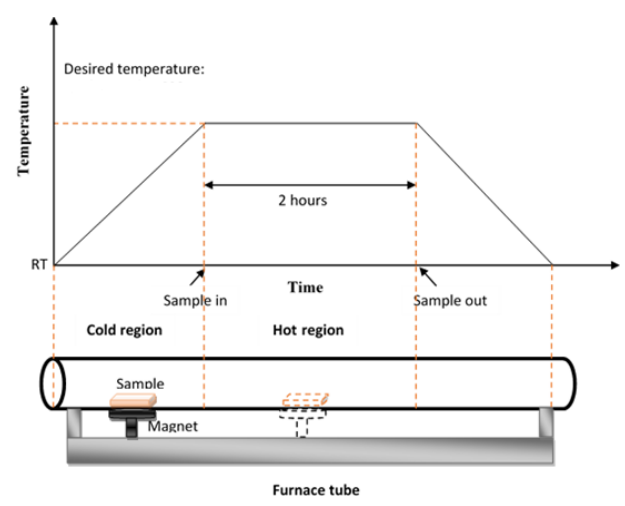

Gambar 4. Skema reduksi termal graphene oxide

\section{Karakterisasi Material}

Ada dua macam karakterisasi yang dilakukan pada penelitian ini yaitu karakterisasi untuk menganalisa defect dan karaketrisasi untuk menganalisa mikrostruktur. Mikrostruktur graphene oxide sebelum dan susadh direduksi dianalisa menggunakan Scanning Electron Microscope (SEM) Hitachi SU-8000 yang diperasikan pada $1 \mathrm{kV}$ milik National Cheng Kung University, Tainan, Taiwan.

Kuantitas defect (cacat) pada lapisan tipis graphene oxide sebelum dan sesudah direduksi dianalisa menggunakan Raman Spectroscopy dengan sumber laser hijau pada panjang gelombang $532 \mathrm{~nm}$.

\section{HASIL DAN PEMBAHASAN}

Graphene oxide sebelum dan sesudah direduksi dikarakterisasi menggunakan Scanning Electron Microscope (SEM) dan Raman Spectroscopy. Berikut ini adalah hasil dan pembahasan pada penelitian ini;

\section{Analisa Defect (Cacat)}

Defect (cacat) pada graphene dapat dianalisa dari hasil Raman spectra nya. Raman spectroscopy merupakan teknik yang tidak merusak material (non-destructive-technique) yang banyak digunakan untuk mengkarakterisasi informasi struktural pada material karbon (carbon-based material). Raman spectra graphene secara umum terdiri dari beberapa karakteristik puncak, yaitu puncak G, puncak D dan puncak 2D yang secara berurutan berada pada $\sim 1350 \mathrm{~cm}-1, \sim 1580 \mathrm{~cm}-1$ dan $\sim 2680 \mathrm{~cm}-1$ (10).

Puncak G menunjukkan optical phonon yang timbul karena getaran pasangan karbon sp2(11). Puncak G umumnya merepresentasikan kuantitas karbon sp2 yang ada pada graphene. Sedangkan puncak D sering digunakan merepresentasikan cacat atau disorder pada graphene karena puncak D muncul disebabkan oleh getaran pasangan karbon yang membutuhkan defect untuk mengaktifkan getarannya (11). Pada penelitian ini akan dibahas pengaruh reduksi termal terhadap defect pada graphene. Gambar berikut adalah Raman spectra dari graphene oxide sebelum dan sesudah tereduksi.

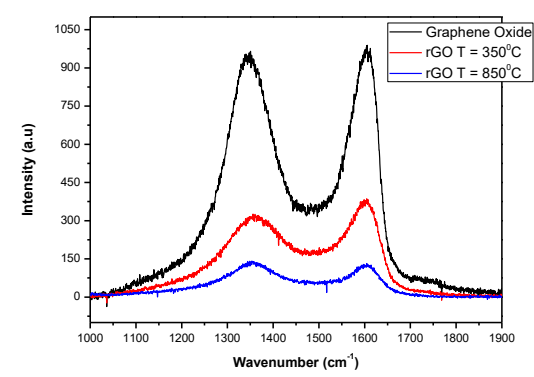

Gambar 4. Raman Spectra dari Graphene oxide (hitam) dan graphene oxide reduksi (rGO) pada temperatur $360^{\circ} \mathrm{C}$ 
Gambar 4 merupakan hasil karakterisasi Raman dari graphene oxide sebelum dan sesudah direduksi. "D peak" graphene oxide yang mengindikasikan derajat kerusakan (disorder) pada graphene berada pada $\sim 1360 \mathrm{~cm}-1$. "G peak" graphene oxide yang merepresentasikan kuantitas sp2 pada graphene berada pada $\sim 1595 \mathrm{~cm}-1$. D peak dan G peak pada graphene oxide sebelum direduksi memiliki intensitas yang tidak terlalu berbeda (comparable). Hal ini ini menunjukkan bahwa graphene oxide memiliki kerusakan struktur tinggi. kerusakan struktur graphene oxide disebabkan oleh oxygen-functional group pada graphene oxide yang memiliki struktur "sp3-carbon" atau "spcarbon" sementara graphene murni (pure Graphene) memiliki struktur "sp2-carbon". Derajat kerusakan pada graphene dapat dianalisa dari nilai rasio antara D-peak dan G-peak (Gambar.5)

Tabel 1. Tabel Nilai ID/IG Graphene Oxide Tereduksi pada berbagai Temperatur

\begin{tabular}{ccc}
\hline No & Reduction Temperture $\left({ }^{0} \mathrm{C}\right)$ & $\mathrm{I}_{\mathrm{D}} / \mathrm{I}_{\mathrm{G}}$ \\
\hline 1 & 0 & 0.958 \\
2 & 350 & 0.823 \\
3 & 850 & 1.102 \\
\hline
\end{tabular}

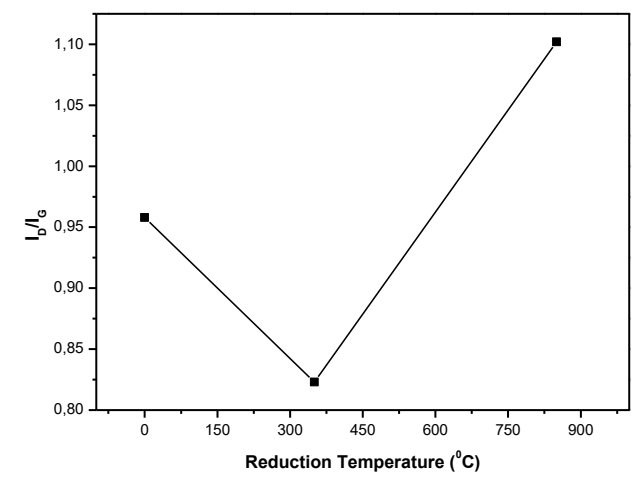

Gambar 5. Grafik hubungan antar a nilai $\mathrm{I}_{\mathrm{D}} / \mathrm{I}_{\mathrm{G}}$ dan temperatur reduksi pada graphene oxide

$\mathrm{I}_{\mathrm{D}} / \mathrm{I}_{\mathrm{G}}$ dari graphene oxide yang direduksi pada temperatur $350^{\circ} \mathrm{C}(\mathrm{rGO} 350)$ lebih rendah daripada $\mathrm{I}_{\mathrm{D}} / \mathrm{I}_{\mathrm{G}}$ graphene oxide sebelum direduksi. Hal ini disebabkan oleh rusaknya ikatan $\mathrm{sp}^{3}$ atau sp yang terbentuk antara karbon dan oxygen-functional group. Ikatan $\mathrm{sp}^{3}$ dan $\mathrm{sp}$ kemudian kembali membentuk ikatan $\mathrm{sp}^{2}$. Proses ini sering disebut $s^{2}$-restoration selama proses reduksi.

Pemanasan pada temperatur $850^{\circ} \mathrm{C}, \mathrm{I}_{\mathrm{D}} / \mathrm{I}_{\mathrm{G}}$ naik secara signifikan yang mengindikasikan kerusakan hebat pada struktur graphene. Pemanasan pada temperatur tinggi membentuk kerusakan struktur lain berupa vakansi pada graphene. Hasil pembentukan vakansi dan porous-material graphene dapat diamati dari SEM-image.

\section{Analisa Mikrostruktur}

Mikrostruktur lapisan tipis graphene oxide dan reduced graphene oxide dapat dianalisa dari hasil gambar SEM nya (Gambar 4) 

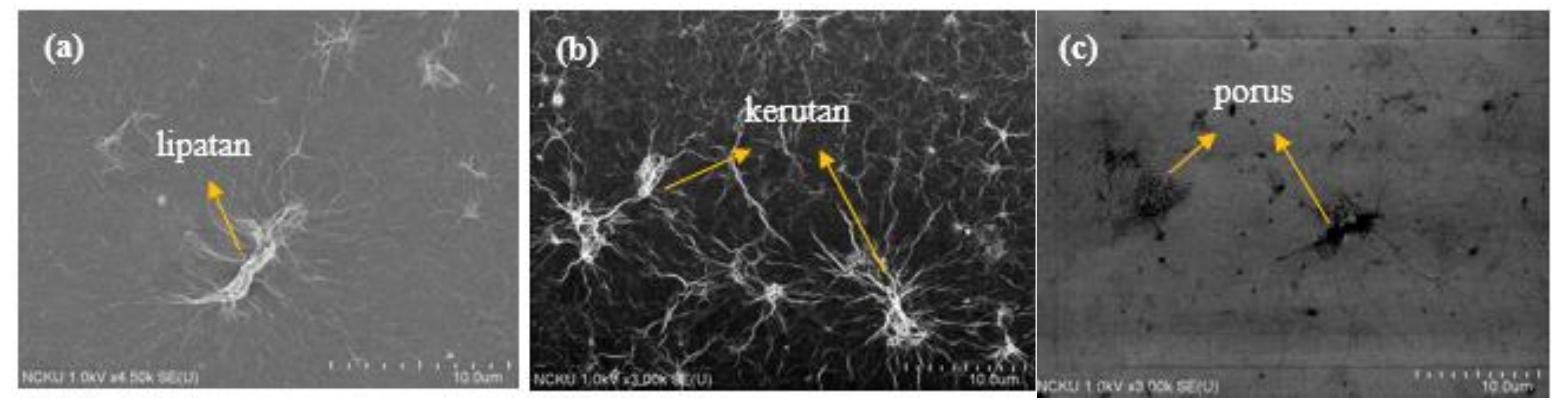

Gambar 6. (a) Image (gambar) permukaan lapisan tipisgraphene graphene oxide (GO), (b) tereduksi pada temperatur $350^{\circ} \mathrm{C}$ dan (c) $850^{\circ} \mathrm{C}$ yang diambil dengan Scanning Electron Microscope (SEM)

Gambar 6 adalah SEM-image dari graphene oxide sebelum dan sesudah direduksi. Spot putih pada SEM-image merupakan lekukan/kerutan lapisan tipis graphene oxide (wrinkle). Jumlah lekukan bertambah saat graphene oxide direduksi pada temperatur $350^{\circ} \mathrm{C}$. Hal ini menyebabkan permukaan lapisan graphene oxide yang terduksi lebih tidak rata daripada sebelum direduksi. Sebagai sensor, bentuk permukaan atau mikrostruktur graphene juga diasumsikan dapat mempengaruhi kemampuan interaksinya terhadap molekul-molekul gas. Setelah direduksi pada temperatur tinggi, yaitu $850^{\circ} \mathrm{C}$ lapisan tipis graphene oxide rusak akibat degradasi ikatan $\mathrm{sp}^{2}$ sehingga membentuk permukaan yang berpori.

\section{SIMPULAN}

Fabrikasi lapisan tipis graphene oxide telah dilakukan dengan metode spin coating. Reduksi termal pada lapisan tipis graphene oxide mempengaruhi mikrostrukurnya seperti yang ditunjukkan pada SEM image. Kuantitas lipatan lapisan tipis rGO bertambah dengan peningkatan temperatur (derajat) reduksi. Pemanasan (reduksi termal) pada temperatur tinggi, yaitu $850^{\circ} \mathrm{Cmampu}$ merusak ikatan $\mathrm{sp}^{2}$-karbon sehingga membentuk material lapisan tipis $\mathrm{rGO}$ berpori (porous-like-rGOmaterial).

Reduksi termal juga diketahhui dapat mengurangi jumlah $\mathrm{sp}^{3}$-karbon dan mengembalikan struktur $\mathrm{sp}^{2}$-karbon ( $\mathrm{sp}^{2}$-restoration) hingga menyebabkan $\mathrm{I}_{\mathrm{D}} / \mathrm{I}_{\mathrm{G}}$ menurun. Sebaliknya, pemanasan (reduksi termal) pada temperatur (derajat) tinggi, yaitu $850^{\circ} \mathrm{C}$ dapat merusak struktur $\mathrm{sp}^{2}$-karbon atau structural disorderyang ditunjukkan oleh peningkatan $\mathrm{I}_{\mathrm{D}} / \mathrm{I}_{\mathrm{G}}$ pada Raman Spectra.

\section{UCAPAN TERIMA KASIH}

Penulis mengucapkan terima kasih kepada berbagai pihak yang berkontribusi dalam penyelesaian tulisan ilimiah ini, terutama kepada Ministry of Science and Technology (MOST) Taiwan yang telah mendanai penelitia ini, Semiconductor and Nanomaterials Laboratorium (SNL) sebagai tempat penelitian ini berlangsung serta tim penelitian graphene oxide yang dipimpin oleh Professor RueyChi Wang dari NUK, Kaohsiung, Taiwan.

\section{DAFTAR ACUAN}

\section{Jurnal}

[1] Measurement of the Elastic Properties and Intrinsic Strength of Monolayer Graphene. Changgu Lee, X.W, Kysar, Jeffry W. dan Hone, James. 2008, Science, hal. 386-388.

[2] Micrometer-Scale Ballistic Transport in Encapsulated Graphene at Room Temperature. Mayorov, Alexander S., et al., et al. 2011, Nano Letters.

[3] Chemical methods for the production of graphenes. Ruoff, S.P.R.S. 2009, Nature Nanotechnology. 
[4] Electric Field Effect in Atomatically Thin Caron Films. K.S. Novoselov, A.K. GEim, S.V. Morozov, D. Jiang, Y.Zhang, S.V Dubonos, I.V. Grigorieva, A.A. Firsov. 2004, Science, hal. 666-669.

[5] The rise of graphene. Novoselov, A.K. Geim and K.S. 2007, Nature Materials, hal. 183-191.

[6] Preparation of Graphene Oxide. William S. Hummers Jr, R.E.O. 1958, Journal of The American Chemical Society, hal. 80.

[7] Graphene Oxide, Highly Reduced Graphene Oxide, and Graphene: Versatile Building Blocks for Carbon-Based Materials. Nguyen, O.C.C. 2010, Small.

[8] Thermal Reduction of Graphene Oxide, in Physics and Application of Graphene-Experiments. Huh, S.H, S.Mikhailov. 2011.

[9] Mechanism of Graphene Oxide Formation. Tour, A.MD.a.J.M. 2014, ACS Nano, hal. 30603068.

[10] Raman Spectrum of Graphene and Graphene Layers. Ferrari, A.C., et al., et al. 2006, Physical Review Letters.

[11] Raman Spectrum of Graphite. Koenig, F.T.a.J.L. 1970, The Journal of Chemical Physics, hal. 1126.

[12] S. Iwan, S.T. Tan, J.L. Zhao, and X.W. Sun, Growth process of $\mathrm{ZnO}$ nanotubes using MOCVD , J. Crystal Growth. 874 (2010), p. 329-333. 
Spektra: Jurnal Fisika dan Aplikasinya http://doi.org/10.21009/SPEKTRA
Volume 2 Nomor 1, April 2017
p-ISSN: 2541-3384 e-ISSN: 2541-3392 